\title{
Anulación, revocación y revisión de oficio en el régimen del reintegro previsto en la Ley general de subvenciones
}

\author{
Ana María Becerra Gómez ${ }^{1}$ (Perú) \\ Universidad de Piura \\ anamaria.becerra@udep.pe
}

\section{NOTA BIOGRÁFICA}

Ana María Becerra Gómez es Abogada por la Universidad de Piura (Perú) y Máster en Estudios Jurídicos Avanzados por la Universidad de Valladolid (España). Profesora ordinaria auxiliar de Derecho administrativo en la Universidad de Piura (Perú). Actualmente es doctoranda en el Departamento de Derecho Público de la Universidad de Valladolid (España) con beca otorgada por la Fundación Carolina desarrollando su investigación sobre la revisión de oficio en el Derecho administrativo español.

\section{RESUMEN}

En el presente artículo, a partir de un breve examen del ámbito objetivo de aplicación de la Ley General de Subvenciones, se analiza críticamente las causas de reintegro de las subvenciones, previstas en los artículos 36 y 37 de dicha Ley. Este análisis tiene como finalidad determinar la regulación de las figuras de anulación y revocación de actos administrativos en el régimen del reintegro y, además, establecer los reales alcances de la revisión de oficio en ese mismo contexto.

\section{PALABRAS CLAVE}

Anulación; revocación; revisión de oficio; reintegro; Ley general de subvenciones.

\begin{abstract}
In this paper, on the basis of a brief review of the objective scope of application of the Spanish General Subsidies Act, the causes of reimbursement of subsidies, as provided for in articles 36 and 37, are critically analyzed. The purpose of this analysis is to determine the regulation of the institutions for invalidation and revocation of administrative acts in the reimbursement of subsidies regime and, furthermore, to establish the actual scope of ex officio review in that same context.
\end{abstract}

\section{KEYWORDS}

Invalidation; revocation; ex officio review; reimbursement.

\section{SUMARIO}

I. INTRODUCCIÓN. II. ÁMBITO OBJETIVO DE APLICACIÓN DE LA LEY GENERAL DE SUBVENCIONES. III. LA OBTENCIÓN DEL REINTEGRO O DEVOLUCIÓN DE LAS SUBVENCIONES COMO PERSPECTIVA DOMINANTE DE LA LEY GENERAL DE SUBVENCIONES EN EL TRATAMIENTO DE LA ANULACIÓN Y DE LA REVOCACIÓN DE LAS SUBVENCIONES A QUE SE APLICA. 1. UBICACIÓN SISValladolid.

1 Profesora de Derecho Administrativo en la Universidad de Piura (Perú). Doctoranda de Derecho Público en la Universidad de 
DA. Nueva Época - N. 5, enero-diciembre 2018 - ISSN: 1989-8983 - DOI: 10.24965/da.v0i5.10616 - [Págs. 107-123]

Anulación, revocación y revisión de oficio en el régimen del reintegro previsto en la Ley general de subvenciones

Ana María Becerra Gómez (Perú)

TEMÁTICA DE LA REGULACIÓN DE LA ANULACIÓN DE LOS ACTOS DE OTORGAMIENTO DE SUBVENCIONES EN LA LEY GENERAL DE SUBVENCIONES. 2. NOCIÓN Y RÉGIMEN DE REINTEGRO. 3. CAUSAS LEGALES DETERMINANTES DE LA OBLIGACIÓN DE REINTEGRO POR INCUMPLIMIENTOS DE BENEFICIARIOS Y ENTIDADES COLABORADORAS. a) Artículo 37.1.b): El incumplimiento total o parcial del objetivo, de la actividad, del proyecto o la no adopción del comportamiento que fundamentan la concesión de la subvención. b) Artículo 37.1.c): Incumplimiento de la obligación de justificación o la justificación insuficiente, en los términos establecidos en el artículo 30 de esta ley, y en su caso, en las normas reguladoras de la subvención. c) Artículo 37.1.d): Incumplimiento de la obligación de adoptar las medidas de difusión contenidas en el apartado 4 del artículo 18 de esta ley. d) Artículo 37.1.e): Resistencia, excusa, obstrucción o negativa a las actuaciones de comprobación y control financiero previstas en los artículos 14 y 15 de esta ley, así como el incumplimiento de las obligaciones contables, registrales o de conservación de documentos cuando de ello se derive la imposibilidad de verificar el empleo dado a los fondos percibidos, el cumplimiento del objetivo, la realidad y regularidad de las actividades subvencionadas, o la concurrencia de subvenciones, ayudas, ingresos o recursos para la misma finalidad, procedentes de cualesquiera Administraciones o entes públicos o privados, nacionales, de la Unión Europea o de organismos internacionales. e) Artículo 37.1.f): Incumplimiento de las obligaciones impuestas por la Administración a las entidades colaboradoras y beneficiarios, así como de los compromisos por éstos asumidos, con motivo de la concesión de la subvención, siempre que afecten o se refieran al modo en que se han de conseguir los objetivos, realizar la actividad, ejecutar el proyecto o adoptar el comportamiento que fundamenta la concesión de la subvención. f) Artículo 37.1.g): Incumplimiento de las obligaciones impuestas por la Administración a las entidades colaboradoras y beneficiarios, así como de los compromisos por éstos asumidos, con motivo de la concesión de la subvención, distintos de los anteriores, cuando de ello se derive la imposibilidad de verificar el empleo dado a los fondos percibidos, el cumplimiento del objetivo, la realidad y regularidad de las actividades subvencionadas, o la concurrencia de subvenciones, ayudas, ingresos o recursos para la misma finalidad, procedentes de cualesquiera Administraciones o entes públicos o privados, nacionales, de la Unión Europea o de organismos internacionales. g) Artículo 37.1.i): En los demás supuestos previstos en la normativa reguladora de la subvención. IV. AUSENCIA DE CUALQUIER REGULACIÓN DE LA REVOCACIÓN DE SUBVENCIONES POR INCUMPLIMIENTO DE LAS OBLIGACIONES DEL BENEFICIARIO O DE LA ENTIDAD COLABORADORA Y SU SUSTITUCIÓN PURA Y SIMPLE POR LA OBLIGACIÓN DE REINTEGRO. V. CONTENIDO DE LA REGULACIÓN DE LA LEY GENERAL DE SUBVENCIONES SOBRE LA REVISIÓN DE OFICIO. 1. REMISIÓN GENERAL EXPLÍCITA A LA LEY 30/92, AHORA LEY 39/2015, Y A LA CAUSA ESPECÍFICA DE NULIDAD RADICAL ESTABLECIDA TRADICIONALMENTE EN LA LEY GENERAL PRESUPUESTARIA, TANTO EN CUANTO A LA REVISIÓN DE OFICIO COMO EN CUANTO A LA ACCIÓN DE LESIVIDAD. 2. DOS EXCEPCIONES EN LAS QUE SE DECLARA NO PROCEDENTE LA REVISIÓN DE OFICIO PARA OBTENER EL REINTEGRO DE LA SUBVENCIÓN ILEGAL. a) Artículo 37.1.a) LGS. 14. b) Artículo 37.1.h) LGS. VI. CONCLUSIONES.

\section{INTRODUCCIÓN}

En el ordenamiento jurídico español, no existe una regulación general sobre ayudas públicas. Sin embargo, sí hay una regulación sobre un tipo de ellas: las subvenciones en la Ley General de Subvenciones (en adelante, LGS). Se trata de una Ley cuyo objeto, según el artículo 1, es la regulación del régimen jurídico general de las subvenciones otorgadas por las Administraciones públicas, régimen estructurado, fundamentalmente, en tres partes: procedimiento de concesión y gestión, reintegro y control financiero de subvenciones.

En el contexto de este régimen, pretendemos analizar críticamente las causas de reintegro de las subvenciones (título II) previstas en los artículos 36 y 37 LGS. Con dicha finalidad, este trabajo se inicia con un breve examen del ámbito objetivo de aplicación de la LGS (con particular referencia al concepto legal de subvención), para pasar a un análisis de la noción y las causas legales de la obligación de reintegro (con el fin de categorizarlas adecuadamente en el marco de la anulación y la revocación de actos administrativos) y finalizar con un sucinto estudio sobre el ámbito de aplicación de la revisión de oficio en materia de reintegro de subvenciones.

\section{II. ÁmBITO OBJETIVO DE APLICACIÓN DE LA LEY GENERAL DE SUBVENCIONES}

El ordenamiento jurídico español regula la figura de la subvención en la Ley 38/2003, de 17 de noviembre, General de Subvenciones (LGS). En su artículo 2 establece el concepto de subvención, señalando que 
se trata de una entrega dineraria sin contraprestación directa de los beneficiarios, sujeta al cumplimiento de determinados objetivos, actividades, comportamientos (realizados o por realizar) que tengan por objeto el fomento de una actividad de utilidad pública o la promoción de una finalidad pública.

Como podemos apreciar, no estamos ante una Ley de ayudas públicas, sino precisamente ante una Ley de subvenciones, en sentido estricto ${ }^{2}$. Por lo tanto, si no hay una entrega dineraria no estaríamos, en principio, ante una subvención. Sin embargo, la propia LGS establece en su quinta disposición adicional que, se «aplicará esta ley, en los términos que se desarrollen reglamentariamente, cuando la ayuda consista en la entrega de bienes, derechos o servicios cuya adquisición se realice con la finalidad exclusiva de entregarlos a un tercero».

Cabe anticipar que, aun teniendo en cuenta lo dispuesto en la quinta disposición adicional a la que hemos hecho referencia, el concepto de subvenciones formulado por la LGS es mucho más reducido que el de ayuda estatal a que se refiere el Tratado de Funcionamiento de la Unión Europea en sus artículos 107 y siguientes (en adelante TFUE), aunque ciertamente las ayudas públicas más frecuentes tomen la forma de subvenciones en el sentido de esta Ley.

En efecto, ha señalado el Tribunal de Justicia de la Unión Europea que se incluyen en la noción de ayuda estatal todas «las decisiones de los Estados miembros que, persiguiendo objetivos sociales y económicos que les son propios, por medio de actos unilaterales ponen a disposición de las empresas o de otros sujetos de derecho recursos o les facilitan ventajas destinadas a favorecer la realización de los objetivos económicos y sociales perseguidos» ${ }^{3}$. Es, pues, evidente, que la noción de subvención de la LGS tiene un alcance más restringido, puesto que comporta una entrega o aportación dineraria, sin comprender cualquier otro tipo de beneficio económico ${ }^{4}$.

La entrega dineraria como elemento característico del concepto de subvención -como veremos que también ocurre con cualquier otra modalidad de ayuda pública, que por ello tienen naturaleza distinta, de suyo, que la donación civil- por lo demás, debe cumplir con un requisito de afectación, es decir, debe estar vinculada al cumplimiento de un determinado fin, que puede ser la ejecución de un determinado proyecto, la realización de una determinada actividad, la observancia de un determinado comportamiento, etc. Y es precisamente esta afectación lo que legitima el otorgamiento dinerario -o el beneficio económico de que se trate, en caso de otras ayudas- correspondiente. Asimismo, es requisito necesario que la entrega dineraria, además de estar afecta a un fin concreto, se realice sin contraprestación directa por parte del beneficiario. En ese sentido, las obligaciones o cargas que asume el beneficiario no se traducen en contraprestaciones -y menos aún de valor equivalente- a favor del otorgante de la subvención ${ }^{5}$.

Conviene advertir que, en el apartado 4 del mismo artículo 2 de la LGS, se excluyen de la noción de subvención los supuestos siguientes:

a) Las prestaciones contributivas y no contributivas del Sistema de la Seguridad Social.

b) Las pensiones asistenciales por ancianidad a favor de los españoles no residentes en España, en los términos establecidos en su normativa reguladora.

c) En la medida en que resulten asimilables al régimen de prestaciones no contributivas del Sistema de Seguridad Social, las prestaciones asistenciales y los subsidios económicos a favor de españoles no residentes en España, así como las prestaciones a favor de los afectados por el virus de inmunodeficiencia humana y de los minusválidos.

d) Las prestaciones a favor de los afectados por el síndrome tóxico y las ayudas sociales a las personas con hemofilia $u$ otras coagulopatías congénitas que hayan desarrollado la hepatitis $\mathrm{C}$ reguladas en la Ley 14/2002, de 5 de junio.

e) Las prestaciones derivadas del sistema de clases pasivas del Estado, pensiones de guerra y otras pensiones y prestaciones por razón de actos de terrorismo.

f) Las prestaciones reconocidas por el Fondo de Garantía Salarial.

\footnotetext{
2 Cfr. SESMA SÁNCHEZ, B. (2011), "El concepto jurídico de subvención y ayuda pública. Alcance de la noción de fomento y promoción", en Derecho de las subvenciones y ayudas públicas, Cizur Menor: Aranzadi, pág. 249.

${ }_{3}$ Sentencia "Denkavit Italiana" de 27 de marzo de 1980, FJ 31. Disponible en: [http://eur-lex.europa.eu/LexUriServ/LexUriServ.do ?uri=CELEX:61979CJ0061:ES:PDF.

${ }^{4}$ Cfr. FERNÁNDEZ FARRERES, G. (2005), "El concepto de subvención y los ámbitos objetivo y subjetivo de aplicación de la ley", en Comentario a la Ley General de Subvenciones, Navarra: Aranzadi, pág. 30. En ese mismo sentido, LÓPEZ RAMÓN, F. (2004), "Ámbito de aplicación de la Ley general de subvenciones", en RAP, núm. 165, pág. 46.

${ }^{5}$ FERNÁNDEZ FARRERES, G., "El concepto de...", cit., págs. 35-37.
} 
g) Los beneficios fiscales y beneficios en la cotización a la Seguridad Social.

h) El crédito oficial, salvo en los supuestos en que la Administración pública subvencione al prestatario la totalidad o parte de los intereses u otras contraprestaciones de la operación de crédito.

La Ley señala que estos supuestos no tienen carácter de subvención; sin embargo, se podría haber prescindido en rigor de dicha enumeración en la medida en que ninguno de ellos podría ser considerado subvención porque no calza en el concepto legal que se recoge en el artículo 2.1 LGS. En ese sentido, como señala parte de la doctrina, esta enumeración legal podría considerarse ejemplificativa y podría haber incorporado otros supuestos que tampoco son calificables como subvención ${ }^{6}$.

Además de esa lista de supuestos que no tienen carácter de subvención, la LGS precisa supuestos calificados como subvenciones «no comprendidas» y «excluidas» de su ámbito de aplicación. A las primeras hace mención la Ley en los apartados 2 y 3 del artículo 2 y a las segundas se refiere el artículo 4 . En ese sentido, considera no comprendidos en el ámbito de aplicación los dos siguientes supuestos:

«las aportaciones dinerarias entre diferentes Administraciones públicas, para financiar globalmente la actividad de la Administración a la que vayan destinadas, y las que se realicen entre los distintos agentes de una Administración cuyos presupuestos se integren en los Presupuestos Generales de la Administración a la que pertenezcan, tanto si se destinan a financiar globalmente su actividad como a la realización de actuaciones concretas a desarrollar en el marco de las funciones que tenga atribuidas, siempre que no resulten de una convocatoria pública»

«las aportaciones dinerarias que en concepto de cuotas, tanto ordinarias como extraordinarias, realicen las entidades que integran la Administración local a favor de las asociaciones a que se refiere la disposición adicional quinta de la Ley 7/1985, de 2 de abril, Reguladora de las Bases del Régimen Local».

Al igual que cuando comentamos aquellas que la ley señala que «no tienen carácter de subvención», en estrictos términos no puede decirse que en estos dos supuestos estemos ante subvenciones que queden excluidas del ámbito de aplicación de la Ley porque así lo determina ella misma, sino que se trata de supuestos que no califican como subvención, de acuerdo con el concepto legal recogido en la norma ${ }^{7}$. En fin, lo que quiere dejar claro la legislación es que estos supuestos no se someten a la Ley, están fuera de su ámbito de aplicación.

Ahora bien, como mencionamos antes, en el artículo 4 LGS se establecen unos supuestos que según el tenor literal quedan excluidos del ámbito de aplicación de la ley. Esos supuestos son los siguientes:

a) Los premios que se otorguen sin la previa solicitud del beneficiario. Según los términos en los que está redactada esta exclusión, parecería que tanto el concepto de subvención como el de premio son equiparables. Sin embargo, sobre lo que se entiende por premio nada dice la LGS. Aunque no se señala un concepto determinado de premio, la LGS en su disposición adicional $10^{\circ}$, «se refiere a unos determinados tipos de premios que, no obstante, dada su descripción, termina englobando o alcanzando a cualesquiera premios» ${ }^{8}$. En efecto, la norma bajo la rúbrica de "Premios educativos, culturales científicos o de cualquier otra naturaleza», señala lo siguiente:

«Reglamentariamente se establecerá el régimen especial aplicable al otorgamiento de los premios educativos, culturales, científicos o de cualquier otra naturaleza, que deberá ajustarse al contenido de esta ley, salvo en aquellos aspectos en los que, por la especial naturaleza de las subvenciones, no resulte aplicable»

De la redacción un tanto imprecisa de la norma, podemos concluir que la equiparación entre premio y subvención no es plena y ello se refleja en lo que dispone la propia LGS, pues excluye del ámbito de aplica-

\footnotetext{
6 FERNÁNDEZ FARRERES, G., "El concepto de...”, cit., pág. 40.

7 Puede verse una explicación detallada de estos supuestos en FERNÁNDEZ FARRERES, G., "El concepto de...", cit., págs. 40-42 y $46-59$.

8 FERNÁNDEZ FARRERES, G., "El concepto de...", cit., pág. 42. El autor deja ver que hay una falta de precisión en el legislador porque la disposición adicional a la que hacemos referencia en el texto «al prever que el correspondiente desarrollo reglamentario pueda no ajustarse a la LGS vincula tal posibilidad a que dicha Ley no resulte aplicable por la especial naturaleza de las subvenciones, lo que hace dudar de si los premios son subvenciones, aunque de especial naturaleza y, por ello no pueden en todo quedar sujetos a la LGS o si, por el contrario, al no ser subvenciones, la regulación reglamentaria de los mismos solo deberá ajustarse en la medida en que la referida regulación no se refiera a aspectos específicos y singulares de las subvenciones».
} 
ción, de una parte a los premios otorgados sin mediar solicitud del beneficiario, y, al mismo tiempo, habilita al Gobierno para que establezca, en el régimen jurídico de todos los demás, las especificidades que en su regulación se precisen. Parece ser que lo más lógico hubiera sido que el legislador estableciera que a los premios no se les aplicase las disposiciones de la LGS porque no pueden calificarse como subvenciones, según el concepto legal, con independencia de que medie o no solicitud del premiado. Dicha previsión, no sería obstáculo para que la legislación específica sobre premios siga algunas de las reglas propias de las subvenciones stricto sensu ${ }^{9}$.

b) Las subvenciones previstas en la Ley Orgánica 5/1985, de 19 de junio, del Régimen Electoral General.

c) Las subvenciones reguladas en la Ley Orgánica 3/1987, de 2 de julio, de Financiación de los Partidos Políticos.

d) Las subvenciones a los grupos parlamentarios de las Cámaras de las Cortes Generales, en los términos previstos en los Reglamentos del Congreso de los Diputados y del Senado, así como las subvenciones a los grupos parlamentarios de las Asambleas autonómicas y a los grupos políticos de las corporaciones locales, según establezca su propia normativa.

Estos tres últimos supuestos que la norma califica como excluidos, en la realidad no calzan en el concepto de subvenciones que la propia ley recoge, puesto que no cumplen con el requisito de afectación. Por lo tanto, aun cuando la LGS no hubiere recogido expresamente su exclusión, no por ello habrían quedado sujetas al régimen general de las subvenciones porque se trata de aportaciones dinerarias que cuentan con una regulación específica en la legislación electoral y en la de financiación de partidos políticos y grupos parlamentarios ${ }^{10}$.

Pensamos que, esta regulación recogida en la norma es poco sistemática, en la medida que tal como está previsto pareciera que los supuestos «no comprendidos en el ámbito de aplicación» y los supuestos «excluidos» son categorías diferentes; sin embargo parecen ser lo mismo, por lo que para una regulación más sistemática hubiere sido mejor recogerlos en un mismo artículo ${ }^{11}$. Aunque, pensamos, el término «no comprendidos» podría hacer referencia a aquellos supuestos que no se comprenden en el concepto de subvención mientras que el considerar que un determinado supuesto es «excluido» puede querer decir que aunque pudiese comprenderse en el concepto, no se someten a la Ley por otras razones.

\section{LA OBTENCIÓN DEL REINTEGRO O DEVOLUCIÓN DE LAS SUBVENCIONES COMO PERSPECTIVA DOMINANTE DE LA LEY GENERAL DE SUBVENCIONES EN EL TRATAMIENTO DE LA ANULACIÓN Y DE LA REVOCACIÓN DE LAS SUBVENCIONES A QUE SE APLICA}

El reintegro de las subvenciones tiene una regulación en un título específico de la LGS. En efecto, el título II LGS trata esta figura y estructura su contenido en 2 capítulos. El capítulo I, de acuerdo a lo recogido

9 FERNÁNDEZ FARRERES, G., "El concepto de...", cit., pág. 43.

10 Cfr. FERNÁNDEZ FARRERES, G., "El concepto de...", cit., pág. 44.

11 Al parecer esta previsión por parte de la LGS, es consecuencia de la observación realizada por el Consejo de Estado al anteproyecto de la misma, que en su texto original no incorporaba las distinciones a las que hemos hecho referencia. Concretamente el Consejo de Estado en su Dictamen 1756/2003 de 26 de junio, hizo la siguiente observación: «El artículo 4 del anteproyecto enumera una serie de ayudas y prestaciones a efectos de excluirlas expresamente del ámbito de la nueva Ley.

Entre estos casos, los contemplados en las letras a) a h) no constituyen verdaderas exclusiones, sino supuestos que en ningún caso estarían incluidos en el ámbito de aplicación de la Ley por no tratarse de subvenciones en el sentido que el artículo 2 del anteproyecto las define. Es el caso, por ejemplo, de las prestaciones contributivas y no contributivas del Sistema de la Seguridad Social (a), las pensiones asistenciales por ancianidad a favor de los españoles no residentes en España (b), las prestaciones a favor de los afectados por el síndrome tóxico y las ayudas sociales a las personas con hemofilia u otras coagulopatías congénitas que hayan desarrollado la hepatitis C reguladas en la Ley 14/2002 (d), las prestaciones reconocidas por el Fondo de Garantía Salarial (f), o los beneficios fiscales y beneficios en la cotización a la Seguridad Social $(\mathrm{g})$.

Sí son verdaderas exclusiones (en la medida en que son supuestos que podrían eventualmente calificarse de subvenciones en el sentido del artículo 2, pero que no quedan sujetas a la nueva Ley por disponer de una normativa específica) los supuestos contemplados en las letras i) a I) del artículo 4: premios que se otorguen sin la previa solicitud del beneficiario (i), subvenciones previstas en la Ley Orgánica de Régimen Electoral General y en la Ley Orgánica de Financiación de partidos políticos ( $\mathrm{j}$ y), y subvenciones a los grupos parlamentarios (I).

En consecuencia, deberían eliminarse de este artículo 3 los supuestos contemplados en sus letras a) a h). Si se estima necesario hacer una referencia a ellos, a efectos de mayor claridad, en el texto del anteproyecto, podría incluirse en el artículo 2, indicando que "no tienen carácter de subvenciones" tales supuestos». 
en el acápite cuarto de la parte expositiva de la propia ley, versa sobre el régimen general de reintegros y el capítulo II, sobre las líneas básicas del procedimiento de reintegro y la competencia para exigirlo. Tal como está estructurada la norma, parece buscar sobre todo la efectividad de reintegro en los casos de ilegalidad o improcedencia que contempla, interesándose sólo secundariamente de la anulación, en su caso, de las correspondientes subvenciones. Es indicativo que la Ley se ocupe de la anulación de las subvenciones dentro del capítulo dedicado al reintegro, por más que ciertamente el reintegro pueda ser, en determinados supuestos, consecuencia de la anulación de una subvención ilegal que hubiera sido efectiva.

Ahora bien, al tratar sobre la revocación de las subvenciones, conviene entender previamente a la revocación como la extinción unilateral, por parte de la Administración, de la eficacia pro futuro de los actos administrativos que constituyan su objeto y de la relación jurídica en su caso generada por ellos, por resultar, en palabras de LAGUNA DE PAZ «ilegales o inoportunas, por falta de cobertura normativa (cambio legislativo o de circunstancias), por cambio de criterios de apreciación o por incumplimiento de su titular» ${ }^{12}$. Considerándose esta definición, la norma no señala específicamente el régimen legal y los supuestos en los que se puede revocar una subvención. De hecho, no hay mención alguna explícita a la revocación. Sin embargo, de lo dispuesto en el artículo 37 LGS se desprende que algunas de las causas que la norma llama «de reintegro» son típicos supuestos de revocación de las subvenciones. Concretamente aquellas causas que se refieren al incumplimiento por parte del beneficiario de la subvención, que ciertamente, darán lugar al reintegro, habrían de producirlo en razón de la revocación de la subvención, más no de su anulación porque ninguna de esas causas se configura como de nulidad o anulabilidad de su concesión.

Siendo este el panorama, procederemos a analizar algunos puntos que pueden ayudarnos a la comprensión de la figura del reintegro y la relación que tiene con la anulación o la revocación de los actos administrativos. Ello, naturalmente, en la medida en que el acto de concesión de una subvención sea un acto administrativo.

\section{Ubicación sistemática de la regulación de la anulación de los actos de otorgamiento de subvenciones en la Ley General de Subvenciones}

Como lo mencionamos anteriormente, el título II de la LGS trata sobre el reintegro, ocupándose en realidad de dos figuras distintas: la invalidez de las resoluciones que otorgan subvenciones (artículo 36) y el reintegro (artículo 37 y ss.). Consideramos que ambas figuras, reintegro y anulación, responden a un régimen jurídico diferente; sin embargo habría que buscar una razón por la cual el legislador ha decidido tratar el régimen de anulación en el título y capítulo del régimen general del reintegro.

La doctrina ha manifestado que lo que podría justificar que bajo dicho título se hayan tratado estas figuras parece ser el hecho de que ambas dan lugar a la obligación de devolver lo recibido en concepto de subvención. Para el caso de la invalidez del acto de concesión, la obligación de devolver lo percibido es una de sus consecuencias eventuales, mientras que para el reintegro, es su consecuencia por antonomasia, por no decir que consiste pura y simplemente en eso mismo ${ }^{13}$.

\section{Noción y régimen de reintegro}

Como hemos mencionado anteriormente, la figura del reintegro la encontramos regulada en el título II de la LGS. En dicho título se integran dos capítulos, el primero que regula el régimen general del reintegro (artículos 36 a 40) y el segundo que regula el procedimiento de reintegro de las subvenciones (artículo 41 a 43). Además de estos preceptos, la figura del reintegro se encuentra regulada en el Real Decreto 887/2006, de 21 de julio, por el que se aprobó el Reglamento de la Ley 38/2003, de 17 de noviembre, General de Subvenciones (en adelante RLGS). Específicamente en el título III de dicho precepto reglamentario se regula el reintegro de las subvenciones.

El reintegro es pura y simplemente la devolución del dinero percibido en concepto de subvención. Esa devolución puede darse como consecuencia de la obligación de devolver que se deriva de la anulación de una subvención que hubiera llegado a hacerse total o parcialmente efectiva, o de la que derive de la revocación ulterior a su dispensación efectiva total o parcial.

12 LAGUNA DE PAZ, J. (2006), La autorización administrativa, Cizur Menor: Thomson - Civitas, pág. 330.

13 Así lo señala, REBOLLO PUIG, M. (2005), "El reintegro de subvenciones", en Comentario a la Ley General de Subvenciones, Cizur Menor: Aranzadi, pág. 407. 
En efecto, el reintegro puede generarse por dos motivos:

1. por la anulación del acto administrativo por el que se concede la subvención, pues al no existir ya el título que sustenta la subvención, parece lógico que como efecto propio de la anulación del acto se produzca el reintegro; y

2. por la existencia de causas, que la LGS llama de reintegro -que bien podrían ser, la mayoría de ellas, causas de revocación- basadas en el incumplimiento de las obligaciones del beneficiario o de los objetivos de la subvención.

Por lo tanto, si se anula o se revoca la subvención, la consecuencia será la misma: el reintegro. Es decir, la devolución de las cantidades que se hayan recibido en concepto de subvención ${ }^{14}$. Sin embargo, la sistemática normativa no es lo suficientemente clara.

A continuación nos referiremos a las causas de reintegro que recoge la LGS en su artículo 37 . No sin antes dejar anotado que la regulación del reintegro que se hace en ese artículo 37 -que alguna doctrina considera en sentido restringido- prescinde de la incidencia en la validez del acto administrativo de concesión de la subvención. En efecto, el artículo 36.5 LGS referido a la invalidez señala que al concurrir alguna de las causas del artículo 37 LGS -entiéndase este concurrir para el caso que alguna de las causas del artículo 37 entre además en una de las causas del artículo 36, referidas a la invalidez de la subvención- no procederá la revisión de oficio, sino solamente el procedimiento de reintegro. Esto que mencionamos puede producir un choque con el régimen general de la invalidez, sobre todo con el de la nulidad de pleno derecho, puesto que, aun cuando se podría eliminar el acto del ordenamiento jurídico, eso no será posible. En principio, porque la misma ley establece que no procederá la revisión de oficio porque concurre al mismo tiempo una de las causas de reintegro establecidas en el artículo 37 LGS.

\section{Causas legales determinantes de la obligación de reintegro por incumplimientos de beneficiarios y entidades colaboradoras}

En este apartado nos referiremos a aquellas causas de reintegro de las subvenciones que, en su formulación legal, no tienen relación expresa alguna con la validez del acto de concesión, pero que determinan la procedencia del reintegro de las cantidades indebidamente percibidas con los correspondientes intereses de demora por concurrir, en principio, algún tipo de incumplimiento ${ }^{15}$. Decimos que en principio estas causas de reintegro se derivan de algún tipo de incumplimiento porque en los supuestos regulados en los apartados a) y h) no estamos ante ningún tipo de incumplimiento de obligaciones derivadas del otorgamiento de la subvención, sino más bien ante posibles causas de anulación del acto administrativo de concesión, si bien, por expreso mandato de la norma, se les excluye de la posibilidad de revisión de oficio y se señala que ha de procederse a la recuperación de lo indebidamente percibido a través del procedimiento de reintegro. En ese sentido, a continuación, trataremos solamente las causas de reintegro que se derivan de algún tipo de incumplimiento de las obligaciones por parte del beneficiario, dejando para un apartado posterior el análisis de aquellas causas de reintegro reguladas en los apartados a) y h) del mencionado artículo 37 LGS.

\section{a) Artículo 37.1.b): El incumplimiento total o parcial del objetivo, de la actividad, del proyecto o la no adopción del comportamiento que fundamentan la concesión de la subvención}

Una de las obligaciones que asume el beneficiario de la subvención, de acuerdo a lo establecido en el artículo 14.1.b) LGS es cumplir «los requisitos y condiciones, así como la realización de la actividad y el cumplimiento de la finalidad que determinen la concesión o disfrute de la subvención».

Asimismo, esta causa de reintegro debemos concordarla con lo establecido en el artículo 91 RLGS que señala lo siguiente:

«El beneficiario deberá cumplir todos y cada uno de los objetivos, actividades, y proyectos, adoptar los comportamientos que fundamentaron la concesión de la subvención y cumplir

${ }^{14}$ Cfr. MARTÍNEZ GINER, L., El reintegro de las subvenciones..., cit., págs. 60-61.

15 Cfr. RODRIGO LAVILLA, J. (2011), "Revocación y reintegro de subvenciones", en Derecho de las subvenciones y ayudas públicas, Cizur Menor: Aranzadi, pág. 506. 
los compromisos asumidos con motivo de la misma. En otro caso procederá el reintegro total o parcial, atendiendo a los criterios establecidos en las bases reguladoras de la subvención».

En ese sentido, independientemente de la naturaleza jurídica de las obligaciones asumidas por el beneficiario de la subvención, de acuerdo a lo establecido en los preceptos mencionados, resulta indiscutible que su incumplimiento conllevará la obligación de restituir los fondos percibidos, ello en la medida que en el acto de concesión de la subvención quedan establecidos los objetivos, proyectos o programas a ejecutar por lo que su no realización o realización parcial determinará, en cada caso, el reintegro ya sea total o parcial de lo percibido ${ }^{16}$. Y es que en la relación jurídico-subvencional, la afectación de la subvención a la actividad o finalidad pública supone, por un lado, la obligación del beneficiario de atenerse a ella (ejerciendo el derecho recibido solo para la realización de la actividad a la que está afectado) y, por otro, la potestad de la Administración de exigir que se respete y cumpla la afectación y, en su caso, revocar la ayuda concedida ${ }^{17}$. Por lo tanto, el reintegro en este caso se producirá cuando el beneficiario incumpla con su parte de la relación jurídico-subvencional ${ }^{18}$.

El cumplimiento de los compromisos asumidos por el beneficiario debe hacerse en los términos que constan específicamente en el acto de concesión de la subvención y en la normativa específica aplicable, puesto que aun cuando se ejecuten actividades o proyectos distintos y con ello se cumpla el fin público perseguido por la subvención, procederá igualmente el reintegro. Ello es así porque el compromiso asumido por el beneficiario, y al que la ley le otorga relevancia jurídica así como también efectos resolutorios, es el objetivo, actividad, proyecto o comportamiento que se fijó en la concesión ${ }^{19}$.

Según lo establecido por este precepto legal, debemos tener en cuenta que el incumplimiento por parte del beneficiario de la subvención puede ser total o parcial, de manera que en caso de tratarse de un incumplimiento parcial, se aplicará el principio de proporcionalidad, que determinará la cuantía que deberá reintegrarse ${ }^{20}$.

\section{b) Artículo 37.1.c): Incumplimiento de la obligación de justificación o la justificación insuficiente, en los términos establecidos en el artículo 30 de esta ley, y en su caso, en las normas reguladoras de la subvención}

A través de la obligación de justificación se acredita la realización de la actividad o del comportamiento de que se trate, así como también el importe de los gastos concretos por la realización de la actividad o el cumplimiento de las cargas impuestas al beneficiario de la subvención ${ }^{21}$. Esta obligación de justificación, tal como establece la causa de reintegro que comentamos, se encuentra regulada en el artículo 30 LGS. Este artículo a su vez señala que la obligación de justificación se realizará en los términos que reglamentariamente se establezcan. En efecto, el artículo 69 RLGS establece cuáles son las modalidades de justificación de las subvenciones: cuenta justificativa, en sus distintas modalidades, la acreditación por módulos y la presentación de estados contables. En ese sentido, si el beneficiario de la subvención incumple con esa obligación de justificación, ya sea total o parcialmente, la consecuencia jurídica será la obligación de reintegro de las cantidades percibidas.

En cualquier caso, la carga de la prueba del cumplimiento de esta obligación le corresponde al beneficiario de la subvención, de modo que si no existe tal justificación, se entenderá que la actividad o gasto tampoco existen ${ }^{22}$.

Esta causa de reintegro, tiene su desarrollo reglamentario en el artículo 92 RLGS. Este precepto reglamentario considera, a su vez, dos situaciones de incumplimiento de la obligación de justificación:

16 Cfr. AA.VV. (2004) Comentarios prácticos a la nueva Ley general de subvenciones, Valladolid: Lex Nova, págs. $323-324$.

17 Cfr. MARTÍNEZ LÓPEZ-MUÑIZ, J. L. (1989), "La actividad administrativa dispensadora de ayudas y recompensas: una alternativa conceptual al fomento en la teoría de los modos de acción de la Administración pública”, en Libro homenaje al Profesor José Luis Villar Palasí, Madrid: Civitas, pág. 761, en relación con el contenido esencial de las ayudas públicas.

18 Cfr. MARTÍNEZ GINER, L., El reintegro de las subvenciones..., cit., pág. 109.

19 Cfr. AA.VV. Comentarios prácticos a la nueva Ley..., cit., pág. 324. En ese mismo sentido, MARTíNEZ GINER, L., El reintegro de las subvenciones..., cit., págs. 109-110.

20 Cfr. MARTÍNEZ GINER, L., El reintegro de las subvenciones..., cit., pág. 111.

21 Cfr. MARTÍNEZ GINER, L., El reintegro de las subvenciones..., cit., pág. 113.

22 En ese sentido, AA.VV. Comentarios prácticos a la nueva Ley..., cit., pág. 326 y MARTíNEZ GINER, L., El reintegro de las subvenciones..., cit., pág. 114. Así también, STS 4558/2003 de 30 de junio, FJ 3, «la prueba de que las condiciones establecidas para el disfrute de las subvenciones han sido cumplidas corresponde al beneficiario de éstas, en cuyo perjuicio corre, por tanto, la ausencia o insuficiencia de dicha prueba». 
1. Cuando transcurrido el plazo otorgado para la presentación de la justificación, ésta no se hubiera efectuado.

2. Cuando la Administración, en sus actuaciones de comprobación o control financiero, detectara que en la justificación realizada por el beneficiario se hubieran incluido gastos que no respondieran a la actividad subvencionada, que no hubieran supuesto un coste susceptible de subvención, que hubieran sido ya financiados por otras subvenciones o recursos, o que se hubieran justificado mediante documentos que no reflejaran la realidad de las operaciones.

Respecto a la primera de las situaciones recogidas por el RLGS, la doctrina se ha cuestionado, qué sucede en aquellos casos en los que se produce una justificación tardía de la subvención, ¿se trata, en efecto, de una falta de justificación? o, por el contrario, ¿estamos ante un supuesto distinto a efectos de reintegro? La doctrina considera que una vez que ha vencido el plazo previsto en la norma para cumplir con la obligación de justificación y ésta no se hubiere llevado a cabo, «habrá que entender producido el incumplimiento y, en consecuencia, concurrente la causa de reintegro ${ }^{23}$. Del mismo modo lo ha entendido el Tribunal Supremo, señalando en una de sus sentencias que «han de cumplirse las condiciones de fondo, pero también han de cumplirse las condiciones formales que se establezcan relativas al tiempo y forma» ${ }^{24}$.

El segundo supuesto es diferente del comentado anteriormente, ya que se habría realizado la justificación de la subvención, pero en un posterior procedimiento de comprobación dicha justificación es cuestionada. En este caso, lo normal será que antes de decretar el reintegro de la subvención se conceda la posibilidad de subsanar los defectos apreciados en la justificación ${ }^{25}$.

Podemos concluir, entonces, que el espíritu de la Ley es recoger el supuesto de falta de justificación incluyendo en él tanto a la ausencia de justificación como a la realización de la misma fuera del plazo establecido para ello. Afirmamos lo anterior teniendo en cuenta que la propia Ley establece, en el literal c) del artículo 57, que la falta de justificación del empleo dado a los fondos recibidos una vez transcurrido el plazo establecido para su presentación constituye una falta grave y, del mismo modo, el literal a) del artículo 56 establece que constituye infracción leve la presentación fuera de plazo de las cuentas justificativas de la aplicación dada a los fondos percibidos.

No obstante lo anterior, debe tenerse en cuenta que el RLGS establece en el apartado 3 del artículo 70 la posibilidad de otorgar al beneficiario de la subvención una última oportunidad para presentar la justificación. En ese sentido, se le otorga al beneficiario un plazo adicional e improrrogable de quince días, pasados los cuales sin haberse presentado la justificación procederá el reintegro. Por el contrario, si en dicho plazo el beneficiario cumple con su obligación de justificación no se exigirá el reintegro pero podrán imponerse las sanciones que procedan ${ }^{26}$.

\section{c) Artículo 37.1.d): Incumplimiento de la obligación de adoptar las medidas de difusión contenidas en el apartado 4 del artículo 18 de esta ley}

Esta causa de reintegro tiene su origen en el incumplimiento de la obligación recogida en el apartado 4 del artículo 18 LGS, que establece que los beneficiarios de una subvención deberán dar «la adecuada publicidad del carácter público de la financiación de programas, actividades, inversiones o actuaciones de cualquier tipo que sean objeto de subvención, en los términos reglamentariamente establecidos».

A su vez el artículo 93 RLGS establece que:

«procederá el reintegro por incumplimiento de la adopción de las medidas de difusión de la financiación pública recibida cuando el beneficiario no adopte las medidas establecidas en las bases reguladoras ni las medidas alternativas propuestas por la Administración y previstas en el artículo 31.3 de este Reglamento».

Es precisamente ese artículo 31 del Reglamento el que desarrolla la obligación de adecuada publicidad por parte del beneficiario, concretando que se procederá al reintegro si no se da la publicidad debida ante

\footnotetext{
${ }^{23}$ AA.VV. Comentarios prácticos a la nueva Ley..., cit., pág. 328. Así también, REBOLLO PUIG, M., "El reintegro de subvenciones...", cit. pág. 438, «según la LGS procederá la devolución aunque finalmente quede perfectamente acreditado que se ha realizado la actividad que fundamenta la subvención».

24 STS 4553/2005 de 07 de julio, FJ 4.

25 Cfr. MARTíNEZ GINER, L., El reintegro de las subvenciones..., cit., pág. 117.

${ }^{26}$ Cfr. MARTÍNEZ GINER, L., El reintegro de las subvenciones..., cit., pág. 118.
} 
el requerimiento último del órgano concedente para que en el plazo no superior a quince días se proceda a la misma ${ }^{27}$.

Esta causa de reintegro ha sido criticada por un sector de la doctrina, pues entiende que el reintegro aquí juega como una sanción que sería muy severa y hasta desproporcionada, puesto que se trata del incumplimiento de una obligación formal donde normalmente el beneficiario tendrá que devolver el dinero que percibió aun cuando se haya empleado en la actividad subvencionada, lo cual puede suponerle un perjuicio grave $^{28}$. Esa misma crítica fue emitida por el Consejo de Estado en su momento, «podría reconsiderarse establecer entre las causas de reintegro de la subvención el incumplimiento de una obligación de carácter accesorio como es la de adoptar las medidas de difusión contenidas en el artículo 18.4 de la Ley (letra d) del apartado 1 del artículo 37). Habida cuenta la naturaleza de esta obligación, podría tipificarse su incumplimiento como infracción administrativa, en lugar de como causa de reintegro» ${ }^{29}$.

En cualquier caso, consideramos que, muy especialmente, en esta causa de reintegro habrá de prestarse atención al principio de proporcionalidad a fin de cuantificar las cantidades que, en cada caso, tengan que reintegrarse ${ }^{30}$.

d) Artículo 37.1.e): Resistencia, excusa, obstrucción o negativa a las actuaciones de comprobación y control financiero previstas en los artículos 14 y 15 de esta ley, así como el incumplimiento de las obligaciones contables, registrales o de conservación de documentos cuando de ello se derive la imposibilidad de verificar el empleo dado a los fondos percibidos, el cumplimiento del objetivo, la realidad y regularidad de las actividades subvencionadas, o la concurrencia de subvenciones, ayudas, ingresos o recursos para la misma finalidad, procedentes de cualesquiera Administraciones o entes públicos o privados, nacionales, de la Unión Europea o de organismos internacionales

Para la configuración de esta causa de reintegro, se requiere la concurrencia simultánea de tres circunstancias: 1) En primer lugar se requiere una conducta activa de la Administración por la que intente la comprobación de la subvención; 2) Asimismo, se requiere de una conducta, activa o pasiva, por parte del beneficiario o entidad colaboradora, que en este caso concreto, y a tenor de lo establecido en el precepto legal, podrá ser: resistencia, excusa, obstrucción o negativa a las actuaciones de control financiero, incumplimiento de obligaciones contables, registrales o conservación de documentos; 3) Finalmente, la norma establece una exigencia a adicional, sin la cual no se podría configurar esta causa de reintegro: es necesario que la conducta del beneficiario o entidad colaboradora tenga como resultado la imposibilidad de verificar el empleo dado a los fondos, el cumplimiento del objeto de la subvención, la realidad de las actividades subvencionadas o su adecuada financiación ${ }^{31}$.

La concurrencia de este último requisito lo recalca especialmente la exposición de motivos de la norma en su apartado IV como si se tratara de una nota común a las causas de reintegro. En ese sentido, la resistencia, excusa o negativa a las actuaciones de comprobación y control financiero por parte de la Administración, así como el incumplimiento de las obligaciones contables, registrales o de conservación de documentación, solamente darán lugar al reintegro cuando no existan medios alternativos que puedan ser empleados por la Administración para alcanzar el objeto de dichas actividades ${ }^{32}$.

Finalmente, estas conductas a que hace referencia esta causa de reintegro están delimitadas en el artículo 56 LGS, en cuyo literal g), establece que constituyen, entre otras, resistencia, obstrucción, excusa o negativa las siguientes conductas:

«No aportar o no facilitar el examen de documentos, informes, antecedentes, libros, registros, ficheros, justificantes, asientos de contabilidad, programas y archivos informáticos, siste-

${ }^{27}$ Cfr. MARTÍNEZ GINER, L., El reintegro de las subvenciones..., cit., pág. 119.

${ }^{28}$ En ese sentido, REBOLLO PUIG, M., "El reintegro de subvenciones...", cit. pág. 440, «no se trata de devolver un dinero que se percibió y que, a fin de cuentas, no se ha empleado en realizar la actividad subvencionada, sino que en todos estos el beneficiario habrá gastado toda la subvención y normalmente mucho más en el proyecto previsto de modo que la devolución de la subvención puede suponerle un perjuicio grave».

29 DCE 1756/2003 de 26 de junio, sobre Anteproyecto de la Ley general de subvenciones.

30 En ese sentido, AA.VV. Comentarios prácticos a la nueva Ley..., cit., pág. 329.

${ }_{31}$ Cfr. REBOLLO PUIG, M., "El reintegro de subvenciones...", cit. pág. 438 y AA.VV. Comentarios prácticos a la nueva Ley..., cit., pág. 329 .

${ }^{32}$ AA.VV. Comentarios prácticos a la nueva Ley..., cit., pág. 329. 
mas operativos y de control y cualquier otro dato objeto de comprobación; no atender algún requerimiento; la incomparecencia, salvo causa justificada, en el lugar y tiempo señalado; negar o impedir indebidamente la entrada o permanencia en locales de negocio y demás establecimientos o lugares en que existan indicios probatorios para la correcta justificación de los fondos recibidos por el beneficiario o la entidad colaboradora o de la realidad y regularidad de la actividad subvencionada; las coacciones al personal controlador que realice el control financiero».

Asimismo, la norma prevé que estas conductas constituyen infracciones administrativas. En efecto, las conductas descritas se considerarán infracciones muy graves, de acuerdo a lo establecido en el artículo 58.c) LGS, cuando imposibiliten de todo punto la comprobación del empleo dado a los fondos percibidos en concepto de subvención así como el cumplimiento de la finalidad de la misma. Sin embargo, cuando esas conductas no impidan el control, se entenderá que se ha configurado una infracción leve ${ }^{33}$.

e) Artículo 37.1.f): Incumplimiento de las obligaciones impuestas por la Administración a las entidades colaboradoras y beneficiarios, así como de los compromisos por éstos asumidos, con motivo de la concesión de la subvención, siempre que afecten o se refieran al modo en que se han de conseguir los objetivos, realizar la actividad, ejecutar el proyecto o adoptar el comportamiento que fundamenta la concesión de la subvención

Esta causa de reintegro se configura automáticamente a través del incumplimiento de las obligaciones impuestas por la Administración o de los compromisos asumidos con motivo de la concesión de la subvención por parte de las entidades colaboradoras o beneficiarios. No se requiere que concurra, además, un impedimento para la verificación de algún aspecto de la subvención o del destino de los fondos percibidos, bastando, en este supuesto, simplemente que el incumplimiento se refiera a obligaciones o compromisos que afecten el modo en que se ha de conseguir el objetivo, realizar la actividad, ejecutar el proyecto o adoptar el comportamiento requerido con motivo de la concesión de la subvención ${ }^{34}$.

Por lo tanto, podemos afirmar que a esta causa de reintegro se le da el mismo tratamiento que aquella establecida en el literal b) del artículo 37.1 LGS, es decir incumplimiento del objetivo o no realización de la actividad que motivó la concesión de la subvención ${ }^{35}$. En ese sentido, esta causa de reintegro que comentamos viene a ser una concreción de aquella que se configura por el incumplimiento total o parcial del objetivo, o la no realización de la actividad, proyecto o conducta (Artículo 37.1.b. LGS); de modo que se da el mismo tratamiento al cumplimiento defectuoso del objetivo, conducta, actividad o proyecto, que a su cumplimiento total o parcial ${ }^{36}$.

f) Artículo 37.1.g): Incumplimiento de las obligaciones impuestas por la Administración a las entidades colaboradoras y beneficiarios, así como de los compromisos por éstos asumidos, con motivo de la concesión de la subvención, distintos de los anteriores, cuando de ello se derive la imposibilidad de verificar el empleo dado a los fondos percibidos, el cumplimiento del objetivo, la realidad y regularidad de las actividades subvencionadas, o la concurrencia de subvenciones, ayudas, ingresos o recursos para la misma finalidad, procedentes de cualesquiera Administraciones o entes públicos o privados, nacionales, de la Unión Europea o de organismos internacionales

Esta causa de reintegro, en sus términos, se parece mucho a la comentada anteriormente, pero exige, además del incumplimiento, de las obligaciones o compromisos, que se derive la imposibilidad de verificar el empleo dado a los fondos, el cumplimiento del objeto de la subvención, la realidad de las actividades subvencionadas o su adecuada financiación. En ese sentido, seguirá el mismo tratamiento que el supuesto de resistencia, obstrucción, excusa o negativa a las actuaciones de comprobación y control ${ }^{37}$.

Asimismo, podemos mencionar que la jurisprudencia ha interpretado uniformemente esta causa de reintegro, entendiendo que «de la recta interpretación de las normas anteriores reguladoras de las bases de

\footnotetext{
33 Cfr. MARTÍNEZ GINER, L., El reintegro de las subvenciones..., cit., pág. 121.

34 Cfr. AA.VV. Comentarios prácticos a la nueva Ley..., cit., pág. 330.

35 Cfr. MARTÍNEZ GINER, L., El reintegro de las subvenciones..., cit., pág. 126.

36 Cfr. AA.VV. Comentarios prácticos a la nueva Ley..., cit., pág. 330.

37 Cfr. AA.VV. Comentarios prácticos a la nueva Ley..., cit., pág. 330
} 
las convocatorias de tales ayudas públicas y de la jurisprudencia existente sobre esta materia, se desprende que, como regla, cualquier incumplimiento de las obligaciones o condiciones establecidas para el disfrute del beneficio habilitaba a la Administración para un pronunciamiento que obligara a la devolución de lo percibido o disfrutado» ${ }^{38}$.

\section{g) Artículo 37.1.i): En los demás supuestos previstos en la normativa reguladora de la subvención}

Esta última causa de reintegro prevista por la Ley constituye una cláusula de cierre, por la que se remite expresamente a la normativa reguladora de la subvención para que en función de su especial naturaleza o fines pueda prever causas de reintegro distintas de las contenidas en el artículo 37 LGS $^{39}$.

Aunque la remisión, en los términos que hace el precepto legal bajo análisis, es bastante amplía, consideramos que la previsión de nuevas causas de reintegro no debería hacerse a través de normas reglamentarias, pues estaríamos antes previsiones que superarían lo regulado por la propia Ley.

\section{AUSENCIA DE CUALQUIER REGULACIÓN DE LA REVOCACIÓN DE SUBVENCIONES POR INCUMPLIMIENTO DE LAS OBLIGACIONES DEL BENEFICIARIO O DE LA ENTIDAD COLABORADORA Y SU SUSTITUCIÓN PURA Y SIMPLE POR LA OBLIGACIÓN DE REINTEGRO}

Hemos dicho antes que la LGS regula, bajo el título que lleva por nombre "Del Reintegro de subvenciones", la invalidez y la obligación de reintegro propiamente dicha.

Ahora bien, como hemos anotado ya, en el apartado anterior, la norma en el artículo 37 establece unos supuestos tasados en los que procede la obligación de reintegro. La gran mayoría de esos supuestos, como hemos podido analizar, se originan por el incumplimiento de las obligaciones o compromisos asumidos por el beneficiario o entidad colaboradora. Por lo tanto, se trata en estricto, de supuestos en los que no se cuestiona la validez del acto de concesión de la subvención ${ }^{40}$, pero en un momento posterior, es decir, ya en la relación jurídica, en los efectos nacidos como consecuencia del acto administrativo de concesión se ha dado una circunstancia -el incumplimiento de la obligación o compromiso asumido- que genera que la efectividad de la subvención sea improcedente (o que se pierda, en una u otra medida, el derecho a la subvención).

Siendo ello así, lo procedente en este caso sería que los efectos de la subvención que han devenido en ilegales, se eliminen del mundo jurídico, precisamente a través de la figura de la revocación. En efecto, como se explicó en un apartado anterior ${ }^{41}$, la revocación de la subvención no mira en nada a la validez del acto de concesión de la subvención sino que, por el contrario, supone dejar sin efecto la subvención -entendida como la relación jurídica nacida del acto de concesión- por incumplimiento por parte del beneficiario de compromisos previamente adquiridos y que debía cumplirlos una vez que se le hubiera concedido la subvención ${ }^{42}$.

Ahora bien, aunque teóricamente esto tendría que ser así, vemos que la LGS, en ningún momento, a lo largo de todo su articulado recoge la figura de la revocación. Sin embargo, pensamos que cuando la norma regula las causas de reintegro de las subvenciones, lo que realmente hace es regular la revocación por incumplimiento (salvo los supuestos contemplados en las letras a y h del artículo 37 que pensamos más bien, constituyen supuestos de invalidez del acto de concesión). En ese sentido, cuando el RLGS desarrolla

38 STS 4558/2003 de $3 .^{\circ}$ de junio, FJ 3. En ese mismo sentido, STS 3402/2003 de 20 de mayo de 2003 , FJ 2.

39 Cfr. AA.VV. Comentarios prácticos a la nueva Ley..., cit., pág. 332, aunque estos autores por la forma en que plantean el análisis de esta causa de reintegro dejan abierta la posibilidad de que se pueda prever una causa de reintegro a través de cualquier tipo de norma, incluso, reglamentaria. Planteamiento con el que no estamos de acuerdo, pues pensamos que la inclusión de nuevos supuestos de reintegro, tendrá que hacerse a través de norma con rango de Ley; en ese sentido, REBOLLO PUIG, M., "El reintegro de subvenciones...", cit. pág. 442.

40 Cfr. RODRIGO LAVILLA, J., "Revocación y reintegro...”, cit., pág. 506, destaca que los supuestos de reintegro considerados por la norma son aquellos en los que «pese a la validez originaria» de la concesión de la subvención «se debe proceder al reintegro de las cantidades indebidamente percibidas junto con los correspondientes intereses de demora al existir alguna desviación respecto del deber ser de la subvención digna de reproche».

41 Vid. introducción del apartado III, supra.

42 En ese sentido, MARTíNEZ GINER, L., El reintegro de las subvenciones..., cit., págs. 80-81, «la revocación de la subvención presupone que el acto de concesión es válido y conforme a Derecho, pero sin embargo la ayuda se deja sin efecto porque el beneficiario incumple las obligaciones y compromisos previamente contraídos»; también, RODRIGO LAVILLA, J., "Revocación y reintegro...", cit., pág. 474. 
una de esas causas de reintegro, utiliza significativamente, aunque sin rigor, el término revocación como sinónimo o equivalente ${ }^{43}$.

Parece que habría sido más acertado, en la medida que contribuiría a una mayor claridad, que el legislador plasmara una regulación con mayor precisión terminológica. De modo que, lo que aparece regulado como reintegro, sea tratado como una consecuencia jurídica que puede darse, ya sea porque la subvención era inválida y se anula, o porque se ha producido un incumplimiento de las obligaciones o compromisos asumidos por el beneficiario o entidad colaboradora que ha justificado la revocación de los efectos de la subvención.

\section{CONTENIDO DE LA REGULACIÓN DE LA LEY GENERAL DE SUBVENCIONES SOBRE LA REVISIÓN DE OFICIO}

\section{Remisión general explícita a la Ley $30 / 92$, ahora Ley $39 / 2015$, y a la causa específica de nulidad radical establecida tradicionalmente en la Ley General Presupuestaria, tanto en cuanto a la revisión de oficio como en cuanto a la acción de lesividad}

El artículo 36 LGS señala que la invalidez del acto de otorgamiento de la subvención puede deberse a alguna de las siguientes causas:

- causas de nulidad o anulabilidad contempladas en el artículo 62.1 de la Ley 30/92 (actuales artículos 47.1 y 48 de la Ley 39/2015); y,

- la concesión de la subvención con insuficiente crédito presupuestario de acuerdo a lo establecido en el artículo 46 de la Ley General Presupuestaria.

Recordemos por lo demás que el artículo 36 LGS contempla, en su apartado 5, la posibilidad de que una causa de invalidez sea al mismo tiempo causa de reintegro conforme al artículo 37 de la misma ley, para cuyo caso se dice que no procederá la revisión de oficio.

Asimismo, podemos dejar apuntado que la LGS no ha establecido ninguna causa de invalidez específica, ya sea de nulidad o anulabilidad, por infracción del Derecho comunitario. Sin embargo, sí ha previsto unas causas de reintegro por ello en el artículo 37.1.h) y 41.2 LGS ${ }^{44}$.

Pensamos que, de acuerdo a lo expresamente previsto por la propia LGS, se puede inferir que el régimen de invalidez de las subvenciones regulado en el artículo 36 se enmarca en el régimen general de invalidez de la Ley 39/2015. El legislador, al declarar expresamente la aplicabilidad del artículo 62 de la Ley 30/92 (actual artículo 47 LPAC) no ha querido quebrar el régimen general de la nulidad de pleno derecho de los actos administrativos. En ese sentido, consideramos que se trata de una postura acertada, en la medida que el acto de concesión de la subvención es, verdaderamente, un acto administrativo, y por lo tanto, si concurre alguna de las causas de nulidad previstas en el régimen general, se produce también la nulidad de la resolución que otorgó la subvención, que en definitiva es también un acto administrativo ${ }^{45}$.

En principio, sería posible incluir en este régimen general aquellas subvenciones que la Unión Europea reputa ilegales, es decir, frente a ellas serían de aplicación todos los medios de reacción para anular actos administrativos. Por ello, cualquier legitimado podrá interponer recursos administrativos o ejercer la acción de nulidad del artículo 106 LPAC o recurrir en vía contencioso-administrativa. Del mismo modo, la Administración pública tiene el deber de proceder de conformidad con los artículos 106 y 107 de la misma ley, según concurran a su juicio causas de nulidad o de anulabilidad ${ }^{46}$. No obstante, ciertamente, en las disposiciones de la Ley 39/2015 sobre validez y sobre revisión de oficio de los actos administrativos no se establece expresamente la posibilidad de que la causa de invalidez del acto administrativo interno sea una infracción del

\footnotetext{
${ }^{43}$ Así lo hace el artículo 31 RLGS, cuando desarrolla la obligación de difusión de la subvención a cargo del beneficiario, en la parte final del literal a) del apartado 3 del mencionado artículo precisa: «No podrá adoptarse ninguna decisión de revocación o reintegro sin que el órgano concedente hubiera dado cumplimiento a dicho trámite» (la cursiva es nuestra).

${ }^{44}$ Cfr. REBOLLO PUIG, M., "El reintegro de subvenciones", cit. pág. 414.

45 Cfr. RODRIGO LAVILLA, J. (2011), "Revocación y reintegro de subvenciones", en Derecho de las subvenciones y ayudas públicas, Cizur Menor: Aranzadi, pág. 479.

${ }^{46}$ Cfr. REBOLLO PUIG, M., "El reintegro de subvenciones..." op. cit. págs. 414-415. El autor señala que es precisamente esa referencia a la revisión de oficio lo que expresamente señala la LGS en su artículo 36.3, pero cree que junto a esa posibilidad que tiene la Administración para instar la revisión de oficio o declarar la lesividad del acto, también existe la posibilidad de conseguir la anulación de la subvención ilegal para cualquier legitimado.
} 
Derecho de la Unión Europea ni tampoco regula de manera específica los instrumentos jurídicos para depurar los actos administrativos internos dictados en infracción del Derecho de la Unión Europea ${ }^{47}$.

Es en este marco jurídico de la nulidad de pleno derecho y la anulabilidad reguladas por la Ley 39/2015, donde se inserta la invalidez de las subvenciones. De hecho la propia LGS al regular el régimen de invalidez de la subvención expresamente remite a las causas de nulidad y anulabilidad contenidas en la LPAC. Sin embargo, esta remisión que resulta tan simple y armoniosa, a primera vista, no lo es del todo en la realidad.

\section{Dos excepciones en las que se declara no procedente la revisión de oficio para obtener el reintegro de la subvención ilegal}

El artículo 36.5 LGS establece que «no procederá la revisión de oficio del acto de concesión cuando concurra alguna de las causas de reintegro contempladas en el artículo siguiente». Por lo tanto, si al lado de una de las causas de invalidez determinantes de nulidad de pleno derecho se configura, además, una causa de reintegro de las contempladas en el artículo 37 LGS, no procederá la revisión de oficio, sino que se preferirá ir directamente al procedimiento de reintegro.

La solución que plantea el citado artículo 36.5 LGS, en sí misma, no parece ocasionar ningún problema. Es más, se puede considerar, hasta cierto punto, muy acertada para lograr el cumplimiento del Derecho comunitario (Artículo 37.1. h). No obstante, en realidad se trata de una solución que podría comportar una excepción a la regla que establece que la Administración pública tiene la potestad de revisar de oficio sus actos nulos. Así, en este supuesto planteado por la norma, no sólo no tiene dicho deber, sino que tiene vedada tal posibilidad ${ }^{48}$.

Esta disposición del artículo 36.5 LGS puede traer ciertas dificultades en la aplicación de la norma, sobre todo porque los supuestos contemplados en los literales a) y h) del artículo 37 LGS cuestionan la validez del acto de concesión. En ese sentido, REBOLLO PUIG plantea algunas cuestiones ${ }^{49}$ :

1. Una primera cuestión es la prescripción del reintegro. Si esto ha ocurrido, ¿puede procederse a la revisión de oficio? Esta pregunta tiene relevancia para la concurrencia de las causas de reintegro con aquellas de nulidad de pleno derecho, pues en estas últimas la revisión de oficio puede realizarse en cualquier momento mientras que el reintegro está sometido a los plazos establecidos en el artículo 39 LGS. Sostener que por concurrir las causas, no es posible realizar la revisión de oficio y menos el reintegro porque ha prescrito la potestad de la Administración para instarlo sería insostenible, puesto que se estaría poniendo a salvo al beneficiario incluso de las consecuencias de la nulidad de pleno derecho. Por lo tanto, lo establecido por el artículo 36.5 LGS debe ser interpretado restrictivamente, de manera que, si ha prescrito el reintegro, será posible y hasta obligado, proceder a la revisión de oficio.

2. Asimismo, se advierte lo siguiente: si la Administración intenta la vía del reintegro sin éxito, porque no se comprueba la existencia de una de las causas del artículo 37, ¿puede después iniciar la revisión de oficio o la declaración de lesividad?

Salta a la vista una respuesta afirmativa. En el supuesto que se plantea, la existencia de una causa de reintegro suponía un «obstáculo» para la revisión de oficio conforme a lo establecido por el artículo 36.5 LGS. Pero una vez comprobada la inexistencia de tal causa, se abre la posibilidad de iniciar el procedimiento correspondiente para la anulación del acto de concesión.

Si la subvención es nula de pleno derecho no habrá inconveniente respecto al trascurso del tiempo; pero si lo que había era un vicio de anulabilidad, existiría el límite temporal de cuatro (04) años (impuesto por el artículo 107 LPAC) que muy probablemente haya transcurrido mientras se tramitaba el procedimiento de reintegro.

En este supuesto cree REBOLLO PUIG, que es posible aceptar que la tramitación del procedimiento de reintegro interrumpe el plazo cuatrienal del artículo 107 LPAC puesto que no se pudo empezar el de declaración de lesividad hasta que se esfumó la apariencia obstativa del artículo 36.5 LGS.

Según estas apreciaciones, el artículo 36.5 LGS posibilita acudir a la vía del reintegro, aun cuando concurra con alguna causa de invalidez, que incluso podría ser alguna de nulidad de pleno derecho; pero

47 ARZOZ SANTISTEBAN, X. (2013), Revisión de actos administrativos nacionales en Derecho Administrativo Europeo, Cizur Menor: Aranzadi, págs. 95-96.

${ }^{48}$ Cfr. REBOLLO PUIG, M., "El reintegro de subvenciones..." op. cit. pág. 423.

${ }^{49}$ Cfr. REBOLLO PUIG, M., "El reintegro de subvenciones..." op. cit. pág. 424-426. 
no quiere decir que, sea imposible seguir la vía para declarar la invalidez por medio de la revisión de oficio $^{50}$.

Por otro lado, pensamos que lo establecido por el artículo 36.5 LGS sobre la no procedencia de la revisión de oficio, tiene sentido en la medida que, ninguna de las causas de reintegro establecidas en el artículo siguiente se configurarían como una causa de nulidad de pleno derecho de las reguladas en el artículo 47 LPAC. Siendo ello así, no es posible que proceda revisión de oficio alguna, pues, según lo establecido por el artículo 106 LPAC, solamente está prevista para los actos viciados de nulidad radical.

Hemos mencionado antes que la mayoría de las causas que la norma señala como de reintegro -que bien podrían ser causas de revocación- presuponen la validez de la concesión de la subvención. Sin embargo, pensamos que merecen especial atención las establecidas en los literales a) y h), que no parten precisamente de la validez del acto administrativo de concesión, sino que más bien tienen como punto de partida la invalidez del acto. Pese a ello el legislador las ha incluido como supuestos en los que procederá el reintegro de la subvención, sin ser necesaria la anulación de los actos administrativos.

\section{a) Artículo 37.1.a) LGS}

El literal a) establece que se procederá al reintegro en el caso que se haya dado la «obtención de la subvención falseando las condiciones requeridas para ello u ocultando aquellas que lo hubieran impedido». Lo establecido en este precepto es claro, puesto que si no se tiene las condiciones necesarias para ser beneficiario de una subvención y pese a ello se ha obtenido, a través de la obrepción o subrepción, resulta más que lógico que se tenga que devolver las cantidades percibidas.

Sin embargo, no deja de parecer obvio, también, el hecho que el acto que concedió la subvención era contrario al ordenamiento jurídico, al momento de dicha concesión y, por lo tanto, inválido.

Ahora bien, si esto es así, ¿en qué causa de invalidez de las reguladas en la Ley 39/2015, podemos encajar este supuesto? En un primer momento podemos afirmar, que encajaría en la causa de nulidad recogida en el artículo 47.1.f) LPAC ${ }^{51}$ : «los actos expresos o presuntos dictados contrarios al ordenamiento jurídico por los que se adquieren facultades o derechos cuando se carezca de los requisitos esenciales para su adquisición». La dificultad que podemos encontrar aquí es determinar cuándo el falsear u ocultar condiciones para la obtención de la subvención implica una carencia de requisitos esenciales, además de la dificultad para determinar cuáles son los requisitos esenciales que se deben cumplir para la obtención de una subvención, teniendo en cuenta, además que, cuando el artículo 9 LGS regula los requisitos para la concesión de una subvención discrimina los requisitos entre esenciales y no esenciales.

Y si en el supuesto que comentamos, se ha adquirido la subvención con la carencia de un requisito que puede considerarse no esencial, queda claro que nos apartamos del supuesto recogido en el artículo 47.1.f) LPAC, por lo tanto, lo más probable será que, tratándose de un requisito no esencial, estemos ante el supuesto de anulabilidad del artículo 48.1 LPAC. Asimismo, debemos tener en cuenta que la causa de reintegro que analizamos exige un plus de engaño que no se recoge en la causa de nulidad de la LPAC.

Pese a este razonamiento, está claro que el legislador ha querido excluir para este supuesto la posibilidad de revisión de oficio y proceder directamente al reintegro. Sin embargo, aun cuando no se declara formalmente la anulación del acto administrativo de concesión se llega a la consecuencia práctica de la misma, puesto que lo que en definitiva se busca es que se devuelvan las cantidades abonadas en concepto de subvención. En este caso en concreto, más que revisar la legalidad y validez del acto, se está castigando la conducta antijurídica del beneficiario cuando solicitó la subvención falseando u ocultando datos esenciales ${ }^{52}$.

Siendo esto así, y para darle un sentido propio a esta causa de reintegro, podríamos insistir en que lo fundamental no son los vicios del propio acto subvencional, sino más bien el comportamiento del beneficiario cuando pidió la subvención y, por lo tanto, es esto último y no aquello lo que será objeto del procedimiento de reintegro y de la resolución que le ponga fin ${ }^{53}$. La existencia de ese plus de engaño en esta causa de reintegro, permite darle un perfil propio e intentar alejarla de la causa de revisión de oficio del artículo 47.1.f) LPAC ${ }^{54}$.

\footnotetext{
50 Cfr. REBOLLO PUIG, M., “El reintegro de subvenciones", cit. pág. 426.

51 Ibidem, pág. 436.

52 En este sentido, advierte MARTÍNEZ GINER, L., El reintegro de las subvenciones..., cit. pág. 108: “... esta causa requiere una conducta que implica cierto dolo; ya sea como acción -la ley se refiere a falsear- o como omisión -la ley se refiere a ocultar-.

53 Cfr. REBOLLO PUIG, M., "El reintegro de subvenciones", cit. pág. 437.

${ }^{54}$ Cfr. MARTÍNEZ GINER, L., El reintegro de la subvenciones..., cit. págs. 107-108.
} 
Asimismo, la doctrina ha entendido que, si de la propia solicitud del interesado se dedujeran los errores, incorrecciones o contradicciones, que finalmente llevaran a la Administración a conceder indebidamente la subvención, ésta solo podría ser objeto de declaración de invalidez y no de reintegro ${ }^{55}$. Esto es así porque se entiende que en tales casos, la Administración debería haber aclarado la situación antes de conceder la subvención. Lo contrario, desde luego, dejaría entrever una conducta negligente de la Administración en el procedimiento de concesión de la subvención que impedirá que la ilegalidad del acto de concesión le sea imputable al perceptor.

Esta construcción, por tanto, parece descansar en la idea de que si la Administración debía haber detectado los errores en la solicitud y no lo hizo, esa ilegalidad no sería imputable al solicitante, y ahora beneficiario de la subvención, sino que se trataría de una negligencia en el actuar administrativo, de lo cual se deduciría la improcedencia del reintegro.

Queda claro que en el supuesto de este literal a) se exige ese elemento intencional de engaño. Asimismo, según la redacción del texto, se deduce que si esos datos falseados u ocultados se hubieren conocido, la concesión de la subvención habría sido imposible. Si se entiende esto así, estaría quedando fuera de la causa de reintegro el supuesto en el que el falseamiento u ocultamiento de los datos no tuviese como objeto la concesión de la subvención, para la cual si reuniría los requisitos necesarios, sino más bien el obtener una cuantía mayor a la que finalmente le correspondería.

Esto ocurriría, por ejemplo, en aquellos supuestos en los que para la obtención de una ayuda a la producción se declara que la cantidad de producción es superior a la real, de manera que se obtiene una ayuda mayor a la que le correspondería. Este vacío legal, en ocasiones, podrá suplirse con el artículo 37.3 LGS, que establece que "procederá el reintegro del exceso obtenido sobre el coste de la actividad subvencionada» ${ }^{56}$. Aunque esto es una salida, sería más armónico dar una respuesta global al problema planteado.

\section{b) Artículo 37.1.h) LGS}

Este literal del artículo 37 establece como causa de reintegro «la adopción, en virtud de lo establecido en los artículos 87 a 89 del Tratado de la Unión Europea de una decisión de la cual se derive una necesidad de reintegro».

Desde luego, esta causa no es una de aquellas que justifique el régimen jurídico de reintegro propiamente dicho ${ }^{57}$. Respecto a este precepto legal debemos aclarar que los artículos 87 a 89 a que se refiere la LGS son actualmente los artículos 107 a 109 TFUE. Asimismo, las decisiones de las que se puede derivar una necesidad de reintegro pueden ser, al hilo de lo establecido en el Reglamento 659/1999, cuando se trata de una ayuda ilegal, es decir, aquellas concedidas por los Estados miembros sin informar previamente a la Comisión, o que aun habiendo informado no se ha esperado el tiempo previsto para entender la compatibilidad de la ayuda con el mercado interior y, por tanto, proceder a su concesión, y un tercer supuesto del que se puede derivar una necesidad de reintegro es aquel que se vincula a las ayudas aplicadas de manera abusiva.

Como podemos apreciar, en este supuesto, la causa por la que se exige la obligación de reintegro, se origina en el acto de otorgamiento de la subvención, por lo tanto, se trataría de una causa de invalidez. Sin embargo, veremos que en el ordenamiento administrativo español tenemos ciertas dificultades para encajar este supuesto en alguna de las causas de nulidad de pleno derecho y, en consecuencia, cumplir en todo momento con la obligación comunitaria de recuperación de ayudas.

\section{CONCLUSIONES}

1. En el ordenamiento jurídico español, no existe una regulación general sobre ayudas públicas. Sin embargo, sí hay una regulación general sobre un tipo de ellas: las subvenciones en la LGS.

55 En ese sentido puede verse: BUENO ARMIJO, A. (2011), El reintegro de subvenciones en la Unión Europea. Especial referencia a las ayudas de la política agraria común, Sevilla: Instituto Andaluz de Administración Pública, pág. 356; MARTíNEZ GINER, L., El reintegro de las subvenciones..., cit. pág. 108.

56 BUENO ARMIJO, A., El reintegro de..., cit. pág. 357.

57 En ese sentido: REBOLLO PUIG, M., "El reintegro de subvenciones", cit., pág. 437 y BUENO ARMIJO, A., El reintegro de..., cit. pág. 391. 
2. El concepto legal de subvención se encuentra previsto en el art. 2.1 LGS. En esta Ley, además, se enumeran varios supuestos que, según expresa la norma, no tienen carácter de subvención («no comprendidos en el ámbito de aplicación») o, siendo considerados «subvenciones» por otras normas, no tienen dicha naturaleza para los fines de la LGS («excluidos»). Se trata, sin embargo, de una regulación poco sistemática, en la medida en que, tal como está previsto, pareciera que ambos tipos de supuestos son categorías diferentes; no obstante, parecen ser lo mismo porque en ningún caso calzan en el concepto legal de subvención del artículo 2.1 LGS. Por tanto, para una regulación más sistemática hubiere sido mejor recogerlos en un mismo artículo.

3. La Ley regula, en el título sobre el reintegro dos regímenes: el de invalidez y el de reintegro. Cuando la norma establece el régimen de invalidez de las subvenciones, hace una remisión al régimen general de invalidez de los actos administrativos (ex artículo 36 LGS). Por su parte, cuando se regula las causas de reintegro, lo que en realidad hace es regular la revocación por incumplimiento (aun cuando la Ley no hace referencia expresa a dicha figura jurídica), salvo los casos contemplados en las letras a y h del artículo 37. Estos últimos supuestos constituyen, más bien, supuestos de invalidez del acto de concesión.

4. Por lo anterior, habría sido más acertado que el legislador recoja una regulación con mayor precisión terminológica. De ese modo, el reintegro debería ser tratado como una consecuencia jurídica que puede tener lugar, por la invalidez y anulación de la subvención o por el incumplimiento de las obligaciones o compromisos asumidos por el beneficiario o entidad colaboradora que justifica la revocación de los efectos de la subvención.

5. El artículo 36.5 LGS prevé que la revisión de oficio del acto de subvención no procede cuando, junto a una de las causas de invalidez, se configura además una causa de reintegro establecida en el art. 37 LGS. En este caso, la Administración deberá dirigirse directamente al procedimiento de reintegro. Aunque esto podría comportar una excepción a la regla según la cual la Administración tiene la potestad de revisar de oficio sus actos nulos, se ha resaltado que, al menos en materia de prescripción y de inexistencia de causa de reintegro, la Administración conserva la mencionada potestad. De este modo, prescrito el reintegro o comprobada la inexistencia de la causa de reintegro, la Administración puede revisar de oficio el acto de concesión, iniciando el correspondiente procedimiento para su anulación. 